\title{
Comparing the Effectiveness of the Frequency and Duration of the Horticultural Therapy Program on Elderly Women with Mild Cognitive Impairment and Mild Dementia
}

\author{
Yong Hyun Kim ${ }^{1,2}$, Hyun Soo $\mathrm{Jo}^{3}$, Chul-Soo Park ${ }^{4}$, Kyungheui Kang ${ }^{5}$, Euy Sun Lee ${ }^{5}$, Su Hyeon Jo ${ }^{5}$, Hwa-Ok Bae ${ }^{6}$, \\ and Moo Ryong Huh ${ }^{2,7^{*}}$ \\ ${ }^{1} \mathrm{Ph}$. D. in Department of Horticulture \& Doctoral program in Social Welfare, Gyeongsang National University, Jinju 52828, Korea \\ ${ }^{2}$ Institute of Agriculture \& Life Science, Gyeongsang National University, Jinju 52828, Korea \\ ${ }^{3}$ Master program in Horticulture, Gyeongsang National University, Jinju 52828, Korea \\ ${ }^{4}$ Professor, Department of Psychiatry, Gyeongsang National University School of Medicine, Jinju 52828, Korea \\ ${ }^{5}$ Public Official of Haman Country Health Center, Haman 52046, Korea \\ ${ }^{6}$ Professor, Department of Social Welfare, Gyeongsang National University, Jinju 52828, Korea \\ ${ }^{7}$ Professor, Department of Horticulture, Gyeongsang National University, Jinju 52828, Korea
}

\section{ABSTRACT}

The purpose of this study was to investigate the effects of the horticultural therapy program on patients with mild cognitive impairment and mild dementia depending on the frequency and duration of the interventions. We developed the same 15-session program to improve cognitive functions and life satisfaction and alleviate depression of the elderly women with mild cognitive impairment or mild dementia. Subjects in Longer Treatment group participated in the program once a week for 15 weeks and subjects in Shorter Tratmet group participated twice a week for $71 / 2$ weeks. This study conducted pretest-posttest verification of both groups using quasi-experimental design involving 21 subjects. Elderly life satisfaction, Geriatric Depression Scale (short form), and the Korean Version of Consortium to Establish a Registry of Alzheimer's Disease (CERAD-K) were used in the evaluation. As a result, both groups showed an increase in life satisfaction, and a decrease in depression. However, there was a significant difference in the changes of the CERAD-K scores between the two groups ( $p<.05$ ). In Longer Treatment group, life satisfaction increased significantly $(p<.001)$, and depression decreased at a marginally significant level $(p=.068)$, but no statistically significant change was observed in neurocognitive function. In Shorter Treatment group, life satisfaction increased at a marginally significant level $(p=.059)$, and depression and CERAD-K scores decreased significantly $(p<.05)$. However, in the case of Mini-Mental State Examination (MMSE-K), there was no significant change in both groups. According to these results, when planning a horticultural therapy program for persons with mild cognitive impairment or mild dementia, it is effective to organize and execute the program by determining the duration of intervention as 3 to 4 months or longer, even if this reduces the number of interventions per week.

Keywords: CAM, CERAD, elderly life satisfaction, GDS, MMSE

\section{Introduction}

Many studies are conducted to alleviate the rapid decline of elderly cognitive functions in mild cognitive impairment (MCI), which is the initial stage of dementia, or before then in order to delay progression to dementia. According to the results, participating in activities using various non-pharmacological intervention techniques that give mental stimulations such as reading, use of computers, arts and crafts, social activities, and various types of games promotes pos-

Received: August 2, 2019, Revised: August 20, 2019, Accepted: February 6, 2020

First author: Yong Hyun Kim, yonghyun@gnu.ac.kr, (iD) https://orcid.org/0000-0003-1913-3041

*Corresponding author: Moo Ryong Huh, mrhuh@gnu.ac.kr, (D) https://orcid.org/0000-0001-8562-4901 
itive well-being and reduces stress, thereby lowering the risk of mild cognitive impairment occurrence in senescence (Krell-Roesch et al., 2019; Mitchell and Agnelli, 2015).

Horticulture and horticultural activities have long been fulfilling various levels of human needs, deeply involved in human life overall from fulfilling basic existence needs to providing stability through contact with nature, mediating relationship building with others, and even embracing aesthetics through sublimation to art (Bengtsson and Grahn, 2014; Berman et al., 2008; Ciftcioglu et al., 2019; Janick, 2014; Kaplan, 1993; Kendle and Forbes, 1997). Fulfillment of needs through horticultural activities as well as the gentle and fascinating experience provided by nature recovers emotional stability and attention of humans and brings positive change to mental health (Kaplan, 1993). Moreover, the longing for nature, which is a basic instinct of humans as part of nature, is the root of this recovery provided by nature (Kellert and Wilson, 1995; Wilson, 2017). In addition, the use of horticultural activities in occupational therapy, which began from the announcement of Benjamin Rush who treated mental patients by digging in the ground, has developed into a field of practical study called 'horticultural therapy' and is now studied extensively (Relf and Lohr, 2003; Simson and Straus, 1997; Smith, 1998).

Many studies have been conducted in horticultural therapy to solve various problems related to dementia as well. According to the results, horticultural therapy reduces depression, anxiety and anger of patients with dementia, promotes them to maintain independence by establishing creative and regular life patterns, and brings positive change that improves self-esteem and quality of life (Blake and Mitchell, 2016). Moreover, in terms of decrease in overall cognitive functions, which is the biggest problem of dementia, horticultural therapy has direct effects on stimulating cognitive functions by giving various sensory stimulations through materials and activities using nature, which does not cause much discomfort to the subjects (Cho, 2008).

With the emerging importance of dementia, horticultural therapy will be one of the most effective interventions in terms of complementary and alternative medicine, which is supported by many studies reporting positive effects of horticultural therapy on dementia, mild dementia and mild cognitive impairment (Blake and Mitchell, 2016; Noone et al., 2017). However, studies thus far have compared the control group without treatment and the group participating in horticultural therapy, or the control group treated with other interventions and the group participating in horticultural therapy, but there is barely any research on the results of performing the same number of sessions of the horticultural therapy program but with a different number of interventions per week.

According to the meta-analysis on the results of horticultural therapy performed on subjects with mental problems, the therapy had the greatest effect when performed total 11-15 times, twice a week, and 1-1.5 hours per session (Kim, 2004). However, Son et al. (2006) mentioned that the duration and number of sessions for the horticultural therapy program must vary depending on the characteristics of the subjects, and reported that it is effective to provide intensive therapy by increasing the number of sessions per week when reducing the duration if the purpose of the program is for physical rehabilitation, and to increase the duration when reducing the number of sessions per week if the purpose is for mental and psychological rehabilitation.

Therefore, this study set the entire duration of the program into Shorter Treatment (twice a week, total 15 sessions) and Longer Treatment (once a week, total 15 sessions) according to the classification by Kim (2004) and Son et al. (2006), and compare the difference between the Shorter Treatment program carried out twice a week according to the meta-analysis result and the Longer Treatment program with a longer duration with reduced weekly sessions according to Son et al. (2006), when the purpose of the program is to improve cognitive functions of subjects with mild cognitive impairment and mild dementia.

\section{Research Methods}

\section{Research model}

To verify the effect of the horticultural therapy program depending on the duration of intervention, we conducted pretest-posttest verification of both groups using quasi-experimental design (Table 1). Both groups carried out the horticultural therapy program comprised of the same activ- 
Table 1. Research design

\begin{tabular}{cccc}
\hline Group & \multicolumn{3}{c}{ Process } \\
\hline Longer Treatment Group & $\mathrm{O}_{1}$ & $\mathrm{X}_{1}$ & $\mathrm{O}_{2}$ \\
Shorter Treatment Group & $\mathrm{O}_{1}$ & $\mathrm{X}_{2}$ & $\mathrm{O}_{2}$ \\
\hline
\end{tabular}

Note. $\mathrm{O}_{1}=$ pre-test; $\mathrm{O}_{2}=$ post-test; $\mathrm{X}_{1}=15$ weeks of horticultural therapy program(once a week); $\mathrm{X}_{2}=71 / 2$ weeks of horticultural therapy program(twice a week).

ities in 15 sessions. The duration of intervention was divided into Longer Treatment and Shorter Treatment program based on the classification by Son et al. (2006).

\section{Subjects and survey method}

\section{Recruitment of subjects}

The objectives and methods of this study were approved by the G University Institutional Review Board (Approval No.: GIRB-A18-Y-0049), after which the study was conducted from September 1, 2018 to May 10, 2019 at a health center located in H-gun, Gyeongsangnam-do. The research was divided into primary and secondary study due to the specificity of the research objective and difficulty in recruiting subjects. The subjects were recruited through the open bulletin board at $\mathrm{H}$ Health Center. The final subjects were selected based on the diagnosis results of the Global Deterioration Scale (GDS) of psychiatrists according to the research objectives (GDS $1=$ no cognitive impairment, GDS 2 = very mild cognitive impairment, GDS $3=$ mild cognitive impairment, GDS $4=$ mild dementia, GDS $5=$ early dementia, GDS 6 = middle dementia, GDS $7=$ late dementia), ultimately selecting 35 elderly women (primary: 20, secondary: 15) at GDS levels 3-4(mild cognitive impairment or mild dementia). Consent to participate in research was obtained from both the selected subjects and their guardians.

\section{Implementation of the horticultural therapy program}

To compare the effects of horticultural therapy according to the research objective, the program with the same number of sessions was carried out while differentiating the total duration and the number of interventions per week. For the primary study, we conducted a Longer Treatment program once a week in total 15 sessions for 15 weeks from October 2, 2018 to January 18, 2019, and for the secondary study, we conducted a Shorter Treatment program twice a week in total 15 sessions for 8 weeks from March 18 to May 10, 2019. The Longer Treatment and Shorter Treatment programs were distinguished based on the classification of the program duration by Son et al. (2006). The main purpose of the program was to improve cognitive functions of the subjects, as well as to alleviate depression reported as a symptom related to cognitive impairment. To attain the purpose, the detailed goal of the program is to stimulate and exercise short-term memory, long-term memory, recall memory and somatesthesia through various horticultural activities. The program is organized with reference to studies that carried out horticultural therapy on subjects with dementia (Kim and Kim, 2012; Kong et al., 2015; Yoo, 2014; Yoon and Sung, 2017). The process of therapeutic intervention in each activity was analyzed to compose the program according to its purpose and goal, with the consultation of one professor in horticultural therapy, one professor in psychiatry, and one $\mathrm{PhD}$ candidate in horticultural therapy (Table 2).

More specific details of the activities are as follows. In Session 1 'Naming flowers and making pressed flower name tags', the subjects were shown photos various flowers, played games of guessing the names of flowers, talked about related stories and recalled related memories to stimulate recall memory. They also selected a flower they want to use its name as their new name to be called in further sessions of the program. After that, they were called by the name of the flower when taking the roll at the beginning of each session so that they could recall their new name. In Session 2 'Making a grass doll', the subjects were to recall memories of each emotion in the topic of joy, anger, sorry and pleasure to stimulate their recall memory, and express their emotions by drawing related facial expressions. Also, they were to portray their own expression of joy on the face of the grass doll. In Session 3 'Making a companion plant', they were to reflect on the meaning of companion animals and name their plants, write them down on the pot, give meaning to them to alleviate their depression and feeling of loneliness. Moreover, using rosemary as a companion plant, the subjects stroked and smelled the plant to stimulate their sensory functions such as touch and smell. 
Table 2. Protocols for horticultural therapy program intervention sessions

\begin{tabular}{|c|c|c|}
\hline Session & Activity & Related plant materials \\
\hline 1 & Pressed flower name tags & - Various pressed flowers \\
\hline 2 & Grass dolls & - Mixed grass \\
\hline 3 & Companion plants & - Rosmarinus officinalis \\
\hline 4 & Terrariums & $\begin{array}{l}\text { - Chamaedorea elegans } \\
\text { - Fittonia spp. }\end{array}$ \\
\hline 5 & Flower arrangement & $\begin{array}{l}\cdot \text { Mixed spray chrysanthemum } \\
\cdot \text { Cornus walteri } \\
\cdot \text { Eucalyptus spp. }\end{array}$ \\
\hline 6 & Collage with seasonal plants & $\begin{array}{l}\text { - For Longer Treatment, Ginkgo biloba, Acer palmatum, Phragmites australis, } \\
\text { Zelkova serrata, Nandina domestica, etc. } \\
\text { - For Shorter Treatment, Rhododendron schlippenbachii, Phlox subulata, } \\
\text { Prunus serrulata var. spontanea, Taraxacum platycarpum, etc. }\end{array}$ \\
\hline 7 & Sowing sprout vegetables & - Brassica oleracea var. italica \\
\hline $8^{\mathrm{z}}$ & Harvesting and cooking sprout vegetables & $\begin{array}{l}\text { - Brassica oleracea var. capitata f. rubra } \\
\text { - Brassica nigra } \\
\text { - Lens culinaris }\end{array}$ \\
\hline $9^{z}$ & Potpourri & $\begin{array}{l}\cdot \text { Rosmarinus officinalis } \\
\cdot \text { Mentha } \times \text { piperita } \\
\cdot \text { Lavandula angustifolia } \\
\cdot \text { Citrus } \times \text { limon }\end{array}$ \\
\hline 10 & $\begin{array}{l}\text { Interior decoration with seasonal plants } \\
\text { (Christmas wreath for Longer Treatment, } \\
\text { Hydroponic cultivation for Shorter Treatment) }\end{array}$ & $\begin{array}{l}\text { - For Longer Treatment, Cornus walteri, Chamaecyparis obtusa, Euphorbia } \\
\text { pulcherrima } \\
\text { - For Shorter Treatment, Hedera helix, Epipremnum aureum }\end{array}$ \\
\hline 11 & Diffusers & $\begin{array}{l}\text { - Rosmarinus officinalis } \\
\text { - Citrus paradisi } \\
\text { - Lavandula angustifolia }\end{array}$ \\
\hline 12 & Scandia moss frames & - Cladonia rangiferina \\
\hline 13 & Pressed flower cards & - Various pressed flowers \\
\hline 14 & Dish gardens & $\begin{array}{l}\text { - Sedeveria Letizia } \\
\text { - Echeveria Tippy } \\
\text { - Echeveria derenbergii } \\
\text { - Sedum clavatum } \\
\text { - Haworthia cymbiformis var. obtusa } \\
\text { - Crassula ovata 'Hobitt' }\end{array}$ \\
\hline 15 & Graduation album and herb tea blending & $\begin{array}{l}\cdot \text { Rosmarinus officinalis } \\
\cdot \text { Matricaria chamomilla } \\
\cdot \text { Mentha } \times \text { piperita } \\
\cdot \text { Melissa officinalis }\end{array}$ \\
\hline
\end{tabular}

${ }^{\mathrm{z}}$ The order is changed in Shorter Treatment program.

In Session 4 'Making a terrarium', the subjects used colored sand to fill up the terrarium, through which they recalled memories of various colors and stimulated their color cognitive function by associating colors with related objects. In Session 5 'Flower arrangement', the subjects classified the prepared flowers by color and counted them, and played games such as holding up the presented number of flowers spoken by the therapist. Then they were to arrange the given number of flowers in the color indicated by the therapist into floral foams, stimulating their cognitive functions about color, number and construct. In Session 6 'Collage with seasonal plants', the subjects re- 
called memories of seasons, touched the plants according to the relevant season to stimulate their sense of touch, and talked about the language of flowers, myth or their personal memories, thereby stimulating recall memory. For Session 6, the mid-term program and Shorter Treatment program were carried out in different seasons and thus different plant materials were used. The Longer Treatment program was carried out in autumn and thus used Ginkgo biloba, Acer palmatum, Phragmites australis, Zelkova serrata, Nandina domestica, etc., whereas the Shorter Treatment program was carried out in spring and thus used Rhododendron schlippenbachii, Phlox subulata, Prunus serrulata var. spontanea, Taraxacum platycarpum, etc. The collage was completed by having the subjects express their own faces on the rough sketch of a face using plant materials after tactile stimulation and recall. In Session 7, the subjects participated in 'Sowing sprout vegetables'. At first the subjects were provided with the names of the plants to sow, and were provided with puzzles mixed with the letters of those names. By searching for the names of the plants in the puzzles, their functions of word recall and word recognition were stimulated. Then, to stimulate constructive functions, the subjects cut the names and stuck them to the sowing containers, and they were to sow plants suitable for each container with its name tag attached. Finally, the subjects were to exercise number cognition by spraying water in the given number of times using a spray. Sessions 8 and 9 were carried out in different orders between the Longer Treatment and Shorter Treatment program due to the time constraints of growing sprouts in Session 7. For the Longer Treatment program, 'Harvesting and cooking sprout vegetables' was carried out in Session 8 and 'Making aromatic potpourri' in Session 9, and vice versa for the Shorter Treatment program. For'Harvesting and cooking sprout vegetables', the subjects harvested the vegetables they sowed in Session 7 and made salads, sandwiches and canapes with them. As they tasted the dishes they cooked together, they were notified that they are midway through the program, and they looked at the photos of their activities carried out thus far to recall them, thus stimulating their memory recall functions. For 'Making aromatic potpourri', the subjects smelled the fragrances of aroma oil and expressed the senses they feel or memories they recall, thereby stimulating both olfactory and memory recall functions. Their sensory cognitive functions were stimulated by expressing what they recalled from the smell in the colors they thought of. In Session 10 'Making interior decorations for each season', the subjects carried out memory recall activities related to the seasons like in Session 6 and made decorations using related plant materials. In the Longer Treatment program, the subjects recalled memories of winter and Christmas, and made Christmas wreaths using Cornus walteri, Chamaecyparis obtusa, and Euphorbia pulcherrima. In the Shorter Treatment program, they recalled memories of summer and made hydroponic flower cups using Hedera helix and Epipremnum aureum.

In Session 11 'Making a diffuser', the subjects made a diffuser by folding paper flowers and using aroma oil to stimulate the order recall and executive functions as well as counting. They folded paper flowers in the order provided by the therapist to stimulate the order recall and executive functions. Their counting function was stimulated by counting the number in the process of putting aroma oil. In Session 12 'Making a Scandia moss frame', the subjects cut out paper according to the shape of objects, arranged it in a frame, colored it and attached Scandia moss that matches the color, which stimulated the constructive functions of the subjects. In Session 13 'Crafts using pressed flowers', the subjects selected the sentence they want and colored it, cut it along the outlines, stuck it to the frame and decorated the surroundings in pressed flowers, which stimulated constructive functions. In Session 14 'Making a dish garden', the subjects wrote down the names of their family members in the family map, compared each succulent to their family members, and talked about memories related to their family members, thereby stimulating their memory recall functions. Finally, in Session 15, they participated in 'Drinking herbal tea and making an album'. They tasted four types of herbal tea and talked about memories or feelings about each tea, thereby stimulating sensory functions such as smell and taste as well as memory recall functions. Then, in making an album as a wrap-up of the entire program, the subjects recalled the memories of the activities by watching slide shows of photos during the 14 sessions of the program. Their memory recall and con- 
structive functions were stimulated by cutting the photos of themselves from each session, sticking them onto designated spots and decorating them.

The program was carried out by one main instructor (Korean Horticultural Therapy \& Wellbeing Association Horticultural Therapist Registered-Grade II) and two assistants (one person with Korean Horticultural Therapy \& Wellbeing Association Horticultural Therapist RegisteredGrade II and one public servant in charge of the health center). Each session was carried out for about 100 minutes including 15 minutes of break time considering the characteristics of the subjects.

\section{Survey items}

The surveys were conducted in terms of age of the subjects, elderly life satisfaction, Geriatric Depression Scale (Short Form), and the Korean Version of Consortium to Establish a Registry of Alzheimer's Disease (CERAD-K). All tests were conducted through the relevant staff at $\mathrm{H}$ Health Center that received specialized training in evaluation.

Elderly life satisfaction was tested using the Memorial University of Newfoundland of Scale for Happiness (MUNSH) developed by Stones and Koza in 1980, which is adapted and modified by Kim (2016) so that it is more suitable to the circumstances in Korea. The scores are rated on a Likert scale from 0 to 2 points, and the range is from 0 to 40 , with higher scores indicating higher life satisfaction. It is comprised of total 20 items, four items each for positive and negative emotions and experiences in everyday life. For negative items, reversed items were used for calculation of the scores. Cronbach's alpha of the tool in the study by Kim (2016) was .927, and in this study it was .705 .

The Geriatric Depression Scale (Short Form) was developed by Kee (1996), and 15 items are answered as either yes or no to calculate the scores. Those with 6 or lower points in total score are in the normal group, those with 6-9 points are considered to have severe symptoms of depression, and those with 10 or higher points have depression. Cronbach's alpha of the tool was .88 when developed, and in this study it was .730 .

The CERAD-K was developed to measure the cognitive functions of patients with dementia, and it is a dementia screening test that combined verbal fluency test, Boston naming test, Korea Version of Mini Mental Status Examination (MMSE-K), word list memory test, constructional praxis test, word list recall test, word list recognition test, and trail making test. In this study, the scores of the CERAD-K were marked by the automatic scoring program (ANSYS in the National Institute of Dementia Safe System, https://ansys.nid.or.kr) depending on the input of the inspector that received specialized training, and thus reliability was not tested. However, in the reliability and validity study of the CERAD-K, the reliability was extremely high with the Pearson correlation coefficient higher than .97 , and the test-retest reliability at a 6-month interval also had the Pearson correlation coefficient of .63-.87 (Lee, 2000).

\section{Analysis method}

To analyze the results after implementing the horticultural therapy program, we excluded the subjects with poor attendance or who did not take the posttest. Accordingly, we conducted analysis using the pretest-posttest data of 13 subjects for Longer Treatment program and 8 subjects for Shorter Treatment program. IBM SPSS Statistics 25.0 Program, a statistical analysis package, was used for analysis. As a result of conducting the Shapiro-Wilk test of normality and homogeneity of variance test on the results of the pretest to determine the data analysis method (Table 3), all items turned out to have normality and homoscedasticity. Accordingly, in addition to the basic descriptive statistics, we used independent samples t-test as a parametric test method to test the intergroup homogeneity before and after the program, and compared the pretest-posttest results through a paired samples t-test.

\section{Results and Discussion}

\section{Characteristics of subjects and preliminary test of homogeneity}

\section{Characteristics of subjects}

The treatment group was composed of women only, and the average age was 81.69 for the Longer Treatment pro- 
Table 3. Tests of normality and equality of variance

\begin{tabular}{|c|c|c|c|c|c|c|}
\hline \multirow{3}{*}{ Variable } & \multicolumn{4}{|c|}{ Shapiro-Wilk normality test } & \multirow{2}{*}{\multicolumn{2}{|c|}{ Levene test }} \\
\hline & \multicolumn{2}{|c|}{ Longer Treatment $(n=13)$} & \multicolumn{2}{|c|}{ Shorter Treatment $(n=8)$} & & \\
\hline & Test statistic & $p$ & Test statistic & $p$ & $\mathrm{~F}$ & $p$ \\
\hline Life satisfaction & .937 & .580 & .881 & .193 & 1.319 & .265 \\
\hline Depression & .871 & .155 & .869 & .146 & 2.041 & .169 \\
\hline CERAD-K & .894 & .253 & .961 & .817 & 3.164 & .092 \\
\hline MMSE-K & .937 & .583 & .884 & .205 & .160 & .694 \\
\hline
\end{tabular}

Note. CERAD-K= Korean Version of Consortium to Establish a Registry of Alzheimer's Disease; MMSE-K=Korean Version of Mini-Mental State Examination.

Table 4. Homogeneity test of subject's characteristics

\begin{tabular}{|c|c|c|c|c|c|}
\hline \multirow{2}{*}{ Variable } & \multicolumn{2}{|c|}{ Longer Treatment $(\mathrm{n}=13)$} & \multicolumn{2}{|c|}{ Shorter Treatment $(\mathrm{n}=8)$} & \multirow{2}{*}{$p$} \\
\hline & $\mathrm{M}$ & SD & M & SD & \\
\hline Life satisfaction & 20.85 & 8.93 & 22.38 & 5.61 & $.670^{\mathrm{NS}}$ \\
\hline Depression & 7.38 & 3.25 & 8.38 & 2.26 & $.461^{\mathrm{NS}}$ \\
\hline CERAD-K & 48.33 & 16.17 & 48.33 & 11.43 & $.251^{\mathrm{NS}}$ \\
\hline MMSE-K & 21.92 & 3.71 & 21.63 & 3.96 & $.863^{\mathrm{NS}}$ \\
\hline
\end{tabular}

Note. CERAD-K = Korean Version of Consortium to Establish a Registry of Alzheimer's Disease; MMSE-K = Korean Version of Mini-Mental State Examination.

${ }^{\mathrm{NS}}$ Non-significant by independent T-test.

gram treatment group $(\mathrm{SD}=3.12)$, and 81.88 for the Shorter Treatment program treatment group $(\mathrm{SD}=4.26)$. The distribution at the level of the Global Deterioration Scale (GDS) to determine MCI or MD, which is the selection standard in recruiting the subjects in advance, was nine subjects in GDS Level 3 and four subjects in GDS Level 4 in Longer Treatment group, and five subjects in GDS Level 3 and three subjects in GDS Level 4 in Shorter Treatment group.

\section{Preliminary test of homogeneity for survey items}

Table 4 shows the results of the preliminary test of homogeneity for the scores of life satisfaction, depression, and neurocognitive functions of the subjects (total score of CERAD and MMSE-K). The results showed that there was no significant difference between the treatment groups. Accordingly, the two experimental groups proved to be homogeneous in terms of scores for life satisfaction, depression, total score of CERAD, and MMSE-K score.

\section{Changes depending on the implementation of the horticultural therapy program}

\section{Life satisfaction}

We conducted between-group posterior mean difference test and pre-post mean analysis by group for the total score and subitems of life satisfaction change of the subjects depending on the implementation of the horticultural therapy program (Table 5). The results of the between-group posterior mean difference test did not show a significant difference in all subitems and the total score. However, as a result of pre-post mean analysis, the group that carried out the mid-term program showed a significant change in the total score of life satisfaction, from 20.85 to 27.00 after the program $(p<.001)$. Moreover, there was a significant level of positive change in the subitems as well. Positive emotion increased from 3.31 to 4.85 ( $p=.024)$, negative emotion from 3.69 to $5.15(p=.019)$, and negative experience from 6.92 to $8.92(p=.007)$ after the program. In the group that carried out the Shorter Treatment program, positive emotion increased from 5.00 to $6.00(p=.086)$ 
Table 5. Comparison of the effects of two horticultural therapy programs on life satisfaction

\begin{tabular}{|c|c|c|c|c|c|c|c|}
\hline \multirow{2}{*}{ Variable } & \multicolumn{3}{|c|}{ Longer Treatment $(n=13)$} & \multicolumn{3}{|c|}{ Shorter Treatment $(\mathrm{n}=8)$} & \multirow{2}{*}{$p^{\mathrm{z}}$} \\
\hline & Pre & Post & $p^{\mathrm{y}}$ & Pre & Post & $p^{\mathrm{y}}$ & \\
\hline Positive emotion & $3.31(2.02)$ & $4.85(2.04)$ & $.024^{*}$ & $5.00(2.33)$ & $6.00(2.20)$ & .086 & .250 \\
\hline Negative emotion & $3.69(2.10)$ & $5.15(2.58)$ & $.019^{*}$ & $3.25(1.39)$ & $4.38(1.51)$ & .161 & .449 \\
\hline Positive experience & $6.92(4.05)$ & $8.08(3.15)$ & .119 & $5.25(2.25)$ & $7.00(4.87)$ & .190 & .543 \\
\hline Negative experience & $6.92(2.40)$ & $8.92(2.75)$ & $.007^{* *}$ & $8.88(1.25)$ & $9.63(2.45)$ & .468 & .562 \\
\hline Total life satisfaction & $20.85(8.93)$ & $27.00(9.41)$ & $<.001^{* * *}$ & $22.38(5.61)$ & $27.00(9.01)$ & .059 & 1.000 \\
\hline
\end{tabular}

Note. Values are mean(standard deviation).

${ }^{\mathrm{z}}$ Post-Post Independent T-test.

${ }^{\mathrm{y}}$ Pre-Post Paired T-test.

${ }^{*} p<.05, \stackrel{* *}{p}<.01, \stackrel{* * *}{p} p<.001$.

Table 6. Comparison of the effects of two horticultural therapy programs on depression

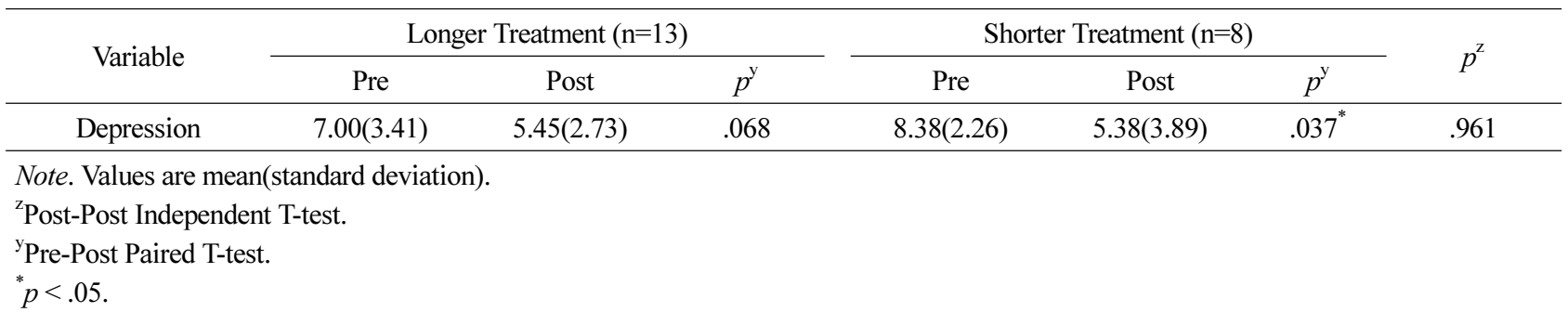

and total score of life satisfaction also increased from 22.38 to $27.00(p=.059)$, although it was not statistically significant. This tendency of increase in life satisfaction through horticultural therapy is similar to the results of previous studies conducted on the elderly with dementia. According to Kong et al. (2015), the subjects gain confidence through the results obtained from carrying out horticultural therapy, and the relief of helplessness in this process helped improve the overall quality of life. Moreover, Gigliotti et al. (2004) also claimed that, compared to the conventional intervention techniques for dementia patients, horticultural therapy is comprised of activities involving plant materials that the subjects are familiar with, thereby increasing their interest as well as participation level and satisfaction, and positively reinforcing the meaning of individual life by helping them focus on 'now-here'. Based on these results, horticultural therapy helps the subjects produce certain outcomes through activities using nature-related materials such as plants. Moreover, satisfaction with the activities as well as immersion in the present by participating in familiar activities that involve plants may have positively changed their thoughts, which had changed negatively due to decrease in cognitive functions. In addition, as for the difference in the effect of horticultural therapy depending on the number of sessions per week and total duration, life satisfaction showed a more significant change in the group that carried out the Longer Treatment program once a week than the group that carried out the Shorter Treatment program twice a week, which was a result similar to Son et al. (2006).

\section{Depression}

We conducted between-group posterior mean difference test and pre-post mean analysis by group for the change in depression of the subjects depending on the implementation of the horticultural therapy program (Table 6). As a result of the between-group posterior mean difference test, there was no significant difference between the treatment groups. As a result of the pre-post mean analysis, both groups showed a decrease in the depression score from severe depression to normal level. In particular, there was a statistically significant decrease after the Shorter Treatment program, from severe depression level at 8.38 to normal level at $5.38(p=.037)$. Moreover, the result of the Longer 
Treatment program showed a difference at a marginally significant level, with a decrease from severe depression level at 7.00 to normal level at $5.45(p=.068)$. This effect of decreasing depression was a similar result as the report by Yoo (2014) and Yoon and Sung (2017), who claimed that horticultural programs had effects on decreasing the depression of elderly with MD. The decrease in depression through horticultural therapy may have been affected by the improved self-expression through various making and gardening activities, as well as the series of tasks and progresses that build cooperative relations by interacting with other participants (Yoo, 2014; Yoon and Sung, 2017).

\section{Neurocognitive functions}

We conducted between-group posterior mean difference test and pre-post mean comparison by group to determine the difference in the effect on neurocognitive functions of the subjects depending on the intervention duration of the horticultural therapy program (Table 7). By subitem of CERAD-K conducted to test the neurocognitive functions, the result of the between-group posterior mean difference test showed that there was a statistically significant difference in only constructional praxis, with the Longer Treatment program group at 8.25 and the Shorter Treatment program group at 5.88 after the program $(p=.003)$. In the pre-post analysis result by group, A showed a significant level of change in verbal fluency from 8.42 to $10.42(p=.026)$, and constructional praxis from 6.92 to $8.25(p=.039)$. $B$ showed a statistically significant decrease in the score for the subitem constructional praxis (7.75 to $5.88, p=.022$ ) and the total score of CERAD-K (55.63 to 47.88). This result indicates that, in areas related to executive functions or regenerative functions like verbal fluency or constructional praxis or semantic memory, the series of activities such as making something or expressing oneself through horticultural therapy may have helped improve such functions when applied for at least a short term (1-2 months). Moreover, the total score of CERAD-K showed an increase, although not significant, in A, whereas it decreased significantly in B. This result indicates that, in implementing horticultural therapy, stimulation of recall memory, various sensory functions, word recall and word recognition in each session prevents decrease of functions due to cognitive impairment when provided to the subjects continuously for at least the mid-term (3-4 months), rather than applying intensive stimulation for a short time, and thus resulted in a difference in total scores even though there was not a significant change to all subitems. As for MMSE-K, there was no significant change in both the between-group posterior mean difference test and pre-post analysis by group. $\mathrm{MCI}$ and $\mathrm{MD}$ are the initial stage of dementia when cogni-

Table 7. Comparison of the effects of two horticultural therapy programs on CERAD-K and MMSE-K

\begin{tabular}{|c|c|c|c|c|c|c|c|}
\hline \multirow{2}{*}{ Variable } & \multicolumn{3}{|c|}{ Longer Treatment $(n=13)$} & \multicolumn{3}{|c|}{ Shorter Treatment $(\mathrm{n}=8)$} & \multirow{2}{*}{$p^{\mathrm{z}}$} \\
\hline & Pre & Post & $p^{\mathrm{y}}$ & Pre & Post & $p^{\mathrm{y}}$ & \\
\hline Verbal fluency & $8.42(2.54)$ & $10.42(3.66)$ & $.026^{*}$ & $9.63(4.03)$ & $8.25(3.33)$ & .270 & .196 \\
\hline Boston naming test & $6.50(2.28)$ & $6.67(.27)$ & .674 & $6.75(2.05)$ & $7.00(2.20)$ & .598 & .749 \\
\hline Word list memory & $13.67(3.55)$ & $13.67(5.53)$ & 1.000 & $18.00(9.84)$ & $12.13(7.68)$ & .122 & .607 \\
\hline Constructional praxis & $6.92(1.93)$ & $8.25(1.66)$ & $.039^{*}$ & $7.75(1.58)$ & $5.88(1.36)$ & $.022^{*}$ & $.003^{* *}$ \\
\hline Word list recall & $3.58(2.02)$ & $4.00(3.07)$ & .499 & $4.38(2.26)$ & $5.50(2.93)$ & .094 & .291 \\
\hline Word list recognition & $7.08(2.91)$ & $6.92(2.78)$ & .853 & $6.75(3.20)$ & $7.13(2.80)$ & .807 & .872 \\
\hline Constructional praxis recall & $2.67(2.10)$ & $2.25(1.49)$ & .546 & $2.38(1.85)$ & $1.88(2.03)$ & .502 & .638 \\
\hline CERAD-K total & $48.33(11.43)$ & $52.00(16.35)$ & .252 & $55.63(16.17)$ & $47.88(15.23)$ & $.047^{*}$ & .620 \\
\hline MMSE-K & $22.17(3.76)$ & $22.33(4.14)$ & .439 & 21.63(3.96) & $20.50(4.24)$ & .351 & .349 \\
\hline
\end{tabular}

Note. Values are mean(standard deviation). CERAD-K=Korean Version of Consortium to Establish a Registry of Alzheimer's Disease; MMSE-K=Korean Version of Mini-Mental State Examination.

${ }^{\mathrm{z}}$ Post-Post Independent T-test.

${ }^{\mathrm{y}}$ Pre-Post Paired T-test.

$\stackrel{*}{p}<.05, \stackrel{* *}{p}<.01$. 
tive functions like memory are declining to an abnormal level (Petersen, 2003; WHO, 2019). The change in the total score of CERAD-K or the score of MMSE-K did not prove the overall improvement of cognitive functions, which is the purpose of this study, but it seems that the Longer Treatment program is more suitable than the Shorter Treatment program in alleviating the decline of cognitive functions of the subjects with MCI and MD.

This result supports the study by Gigliotti et al. (2004) who claimed that the horticultural therapy program carried out on the elderly with MD living in daycare facilities stimulates the memory recall process and helps them recall meaningful memories of the materials, thereby showing effect in alleviating the decline of cognitive functions. Moreover, it is also similar to Yoon et al. (2005) proving that indoor horticultural activities significantly improved psychological stability and cognitive functions of patients with dementia. Furthermore, studies that carried out horticultural therapy on patients with Alzheimer's disease include D'Andrea et al. (2007) who reported that horticultural activities alleviated the decrease of cognitive functions more in the experimental group than the control group. In addition, according to Cho (2008), horticultural therapy improved attention and memory of the elderly with dementia. This improvement in attention and memory may have affected alleviation of decrease in cognitive functions. The results of previous studies verified once again that horticultural therapy is effective in alleviating the decrease of the elderly's cognitive functions.

\section{Conclusion}

This study was conducted to determine the difference in the effects of horticultural therapy depending on the duration of intervention for patients with MCI and MD. The subjects were elderly women with MCI and MD at GDS levels 3-4 in the average age of 81.76 (minimum 76-maximum 86). We developed the same 15 -session program to improve cognitive functions and life satisfaction and alleviate depression of the subjects, and divided into the Shorter Treatment program carried out twice a week for 8 weeks and the Longer Treatment program carried out once a week for 15 weeks. As a result, both groups showed an increase in life satisfaction in the psychological and emotional aspects, decrease in depression, and change in neurocognitive functions in the cognitive aspect. These positive changes were also found in previous studies that carried out horticultural therapy programs on the elderly with $\mathrm{MCI}$ and $\mathrm{MD}$. However, there was a difference in the treatment groups in terms of change in the scores of life satisfaction, depression and neurocognitive functions depending on the number of interventions and duration. Life satisfaction increased in both groups, but a significant level of change was found only in the Longer Treatment program group. Depression showed a severe level in both groups before the program, but after the program it decreased to a normal range at a marginally significant level for the Longer Treatment program and at a significant level for the Shorter Treatment program. There was a difference in the results of the Longer Treatment and Shorter Treatment program for neurocognitive functions. The score increased overall in the Longer Treatment program, although not at a significant level, whereas the total score of CERAD decreased at a significant level in the Shorter Treatment program. As a result of conducting an analysis of covariance to determine the significant difference in the duration of intervention by controlling other variables, the total score of CERAD-K showed a difference depending on the duration. These results were different from previous studies presented by meta-analysis, reporting that the Shorter Treatment intensive program showed better effect. The decline of cognitive functions is a continuous phenomenon according to aging, and thus, instead of temporarily improving the morbid symptoms, a mid-term or longer program may have been more effective in alleviating the decrease of cognitive functions. Furthermore, even though the improvement of cognitive functions, which was the purpose of the horticultural therapy program, was not proved in this study, we could find that the Longer Treatment program alleviated the decrease of cognitive functions. This indicates that the horticultural therapy program not only stimulates cognitive functions through direct horticultural activities but also delays deterioration of cognitive functions in the long run by improving the negative emotional state of the subjects. These results showed that, in planning 
a horticultural therapy program for mental and psychological rehabilitation, it is more effective to organize and implement the program by setting the duration of intervention to be 3-4 months or longer, even if this reduces the number of sessions per week. However, the limitation of this study is that the horticultural therapy program was divided into primary and secondary study in two different periods due to the issue of recruiting the subjects. Accordingly, even though the program was carried out by the same instructor with the same purpose and goal, the different period of the program slightly changed the materials, content and order of the activities in recalling the season, thereby not being perfectly equivalent. The results may also vary depending on this difference. Furthermore, the number of subjects was also very small despite the verification of the normality distribution and the preliminary test of homogeneity, and thus the results of this study cannot be generalized. Therefore, further research must involve additional re-examination according to the duration of the subjects in this study, along with comparison of the different effects depending on the duration in terms of other studies in the psychological and mental aspects.

\section{References}

Bengtsson, A., and P. Grahn. 2014. Outdoor environments in healthcare settings: A quality evaluation tool for use in designing healthcare gardens. Urban For. Urban Green. 13(4):878-891. https://doi.org/10.1016/j.ufug.2014.09.007

Berman, M.G., J. Jonides, and S. Kaplan. 2008. The cognitive benefits of interacting with nature. Psychol. Sci. 19(12): 1207-1212. https://doi.org/10.1111/j.1467-9280.2008.02 225.x

Blake, M. and G. Mitchell. 2016. Horticultural therapy in dementia care: A literature review. Nurs. Stand. 30(21):41-47. https://doi.org/10.7748/ns.30.21.41.s44

Cho, M.K. 2008. Horticultural therapy as non-pharmacological treatment for the improvement of cognitive function and BPSD in dementia. Doctoral dissertation, Konkuk University, Seoul, Korea.

Ciftcioglu, G.C., S. Ebedi, and K. Abak. 2019. Evaluation of the relationship between ornamental plants-based eco- system services and human wellbeing: A case study from Lefke Region of North Cyprus. Ecol. Indic. 102:278-288. https://doi.org/10.1016/j.ecolind.2019.02.048

D'Andrea, S.J., M. Batavia, and N.J. Sasson. 2007. Effect of horticultural therapy on preventing the decline of mental abilities of patients with alzheimer's type dementia. J. Ther. Hortic. 18:9-13.

Gigliotti, C.M., S.E. Jarrott, and J. Yorgason. 2004. Harvesting health: Effects of three types of horticultural therapy activities for persons with dementia. Dementia 3(2):161-180. https://doi.org/10.1177/1471301204042335

Janick, J. 2014. Horticulture and art. In G.R. Dixon \& D.E. Aldous(Eds.), Horticulture: Plants for People and Places, Volume 3 (pp. 1197-1223). Dordrecht, Netherlands: Springer. https://doi.org/10.1007/978-94-017-8560-0

Kaplan, R. 1993. The role of nature in the context of the workplace. Landsc. Urban Plan. 26(1-4):193-201. https://doi.org/10.1016/0169-2046(93)90016-7

Kee, B.S. 1996. A preliminary study for the standardization of geriatric depression scale short form-korea version. J. Korean Neuropsychiatr. Assoc. 35(2):298-307.

Kellert, S.R. and E.O. Wilson. 1995. The biophilia hypothesis. Washington, USA: Island Press.

Kendle, T. and S. Forbes. 1997. Urban nature conservation: landscape management in the urban countryside. London, UK: Thomson Professional.

Kim, H.S. 2016. A comparative study on the life satisfaction between the elderly and the elderly in welfare town: Focusing on the elderly in low income class in Gimje. Master's thesis, Hanil University \& Presbyterian Theological Seminary, Wanju, Korea.

Kim, M.H. and J.M. Kim, 2012. The effect of an occupational therapeutic intervention program using horticultural therapy on cognition and daily living performance of elderly with dementia. J. Korean Soc. Community Based Occup. Ther. 2(1):75-84

Kim, S.H. 2004. Meta-analysis for the effectiveness of researches related to horticultural therapy. Master's thesis, Konkuk University, Seoul, Korea.

Kong, J.H., S.Y. Yun, and B.J. Choi. 2015. The effects of reminiscence-based horticultural therapy on institutionalized demented elders' self-esteem and quality of life. J. Korean Soc. People Plants Environ. 18(4):305-309. 
https://doi.org/ 10.11628/ksppe.2015.18.4.305

Krell-Roesch, J., J.A. Syrjanen, M. Vassilaki, M.M. Machulda, M.M. Mielke, D.S. Knopman, W.K. Kremers, R.C. Petersen, and Y.E. Geda. 2019. Quantity and quality of mental activities and the risk of incident mild cognitive impairment. Neurology 93(6):e548-558. https://doi.org/ 10.1212/WNL.0000000000007897

Lee, D.Y. 2000. A normative study of the Korean version of CERAD neuropsychological test battery[CERAD-K(N)] in elderly. Doctoral dissertation, Seoul National University, Seoul, Korea.

Mitchell, G. and J. Agnelli. 2015. Non-pharmacological approaches to alleviate distress in dementia care. Nurs. Stand. 30(13):38-44. https://doi.org/10.7748/ns.30.13.3 8.545

Noone, S., A. Innes, F. Kelly, and A. Mayers. 2017. 'The nourishing soil of the soul': The role of horticultural therapy in promoting well-being in community-dwelling people with dementia. Dementia 16(7):897-910. https://doi.org/10.1177/1471301215623889

Petersen, R.C. 2003. Conceptual overview. In R.C. Petersen (Ed.), Mild cognitve impairment: Aging to Alzeimer's dissease(pp. 1-14). New York: Oxford University Press.

Relf, P.D. and V.I. Lohr. 2003. Human issues in horticulture. HortScience 38(5):984-993.

Simson, S. and M. Straus. 1997. Horticulture as therapy: Principles and practice. NY, USA: The Haworth Press,
Inc.

Smith, D.J. 1998. Horticultural therapy: The garden benefits everyone. J. Psychosoc. Nurs. Ment. Health Serv. 36(10): 14-21. https://doi.org/10.3928/0279-3695-19981001-12

Son, K.C., M.K. Jo, J.E. Song, S.Y. Kim, and S.S. Lee. 2006. Practice of professional horticultural therapy. Seoul, Korea: KuBook from KonKuk University.

WHO. 2019. Risk reduction of cognitive decline and dementia: WHO guidelines. Retrieved 14 July 2019 from https://www.who.int/mental_health/neurology/dementia/guidelines_risk_reduction/en/

Wilson, E.O. 2017. Biophilia and the conservation ethic. In: Evolutionary perspectives on environmental problems(pp. 263-272). NY, USA: Routledge.

Yoo, C.S. 2014. Verification of efficacy of horticultural therapy program in enhancing life satisfaction \& reducing depression for elderlies with mild dementia. Master's thesis, KonKuk University, Seoul, Korea.

Yoon, M.S. and K.M. Sung. 2017. The effects of a horticultural program based on Coxs Interaction Model on ability for daily life and depression in older patients with mild dementia. Korean J. Rehabil. Nurs. 20(1):12-21. https://doi.org/10.7587/kjrehn.2017.12

Yoon, S.Y., H.Y. Kim, and Y.K. Park. 2005. Effect of horticultural therapy on the improvement of attentiveness and emotional stability of dementia. J. Korean Soc. People Plants Environ. 8(2):1-6. 